\title{
Aproximación al fenómeno laminar en el Paleolítico medio: el ejemplo de Cueva Morín (Villanueva de Villaescusa, Cantabria)
}

\author{
José Manuel Maíllo Fernández ${ }^{1}$
}

\begin{abstract}
RESUMEN
Este trabajo presenta evidencias de esquemas de débitage laminar (de hojitas) en los niveles superiores del musteriense de cueva Morin (niveles 11 y 12). Éste se organiza a partir de núcleos de morfología prismática y explotación unipolar. Los soportes no son muy numerosos, aunque algunos de ellos retocados. Este tipo de esquema en cueva Morin confirma los ya presentados en otros yacimientos con lo que el fenómeno laminar en el

Musteriense cantábrico debe ser considerado como un hecho y no como algo anecdótico.
\end{abstract}

PALABRAS CLAVE Paleolítico Medio, Musteriense, Esquema operativo laminar de hojitas, Cueva Morin, Tecnología lítica.

\section{RÉSUMÉ}

Dans cet travail nous voulons présenter quelques évidences de débitage à lamelles dans las couches du Moustérien tardif à cueva Morin (couches 11 et 12). Il est a partir de nucleus de morphologie prismatique et explotaition unipolar. Les supports ne sont pas très abundants, mais quelques ils sont retouchés.

\section{MOTS CLEF}

Paléolithique Moyen, Moustérien, Schéma operatoire lamellaire, Cueva Morin, technologie lithique.

1 Personal Investigador, Dpto. Prehistoria e Historia Antigua, UNED. E-mail: jlmaillo@geo.uned.es 
Habitualmente asignados al inicio del Paleolítico Superior y al origen de los humanos modernos, los métodos de explotación laminar no son, en absoluto, desconocidos en conjuntos pertenecientes al Paleolítico Medio en Europa y Próximo Oriente. Sin embargo, han sido relegados por otros esquemas cuantitativamente más numerosos y mejor estudiados, como los diferentes métodos Levallois (Révillion, 1994). Además, la subdivisión realizada de la industria lítica Paleolítica a finales del siglo xIx y principios del XX: choppers-bifaces-lascas-hojas, venía acompañada por un paralelismo de tipo biológico. Estas asumpciones se realizaron a partir de un número muy limitado de yacimientos arqueológicos y, aunque tras décadas de estudio y de nuevas excavaciones se demostró que esa «realidad" no es verdadera, se ha mantenido en los libros de Prehistoria (BarYosef \& Kuhn, 1999). Especialmente interesante resulta la perduración de la ecuación Hombre moderno-producción de hojas, sin duda apoyada en la mayor dificultad cognitiva para la producción de dichos soportes frente a los métodos Levallois. A la luz de las actuales investigaciones hemos asistido a la refutación de dicha hipótesis ya que, o la producción de hojas no es más difícil que los métodos Levallois o no es necesaria una mayor capacidad cognitiva para llevarla a cabo.

Pero, ¿qué ventajas aporta la producción y los soportes laminares? En primer lugar, debemos saber qué es una hoja. Dos son los aspectos que permiten reconocer una hoja u hojita. El primero es de tipo métrico, por lo que ha de ser un soporte que sea, al menos, el doble de largo que de ancho. El segundo es de naturaleza tecnológica: ha de presentar una serie de nervaduras paralelas al eje longitudinal de la piezas y la dirección de los negativos anteriores de la cara dorsal también han de ser paralelos. Esta disposición de las extracciones anteriores genera en dichos soportes dos bordes paralelos de filo bruto. Por lo tanto, deben de coexistir elementos morfológicos y tecnológicos (Inizan et alli, 1995). Dos son las concepciones habitualmente empleadas para la realización de soportes laminares: el débitage Levallois y la concepción prismática de los núcleos, este último también denominado «tipo Paleolítico Superior». Aquí nos vamos a referir a este tipo de débitage para caracterizar las ventajas de la producción laminar.

Los soportes laminares aportan varios elementos importantes de carácter económico, uno de ellos es la noción de estandarización (Tixier, 1984). La producción de soportes laminares a partir de un núcleo preparado permite la extracción de un gran número de soportes de características similares. Además, en el caso de los núcleos prismáticos, es posible controlar las dimensiones de dichos soportes. La producción de hojas, al ser un método estandarizado y recurrente, permite la obtención 
de un número de soportes mayor que bajo otros métodos con igual cantidad de materia prima, lo que genera más cantidad de filo útil. Por último, las hojas permiten una mejora en los métodos de enmangue y aprehensión y permiten un mejor reavivado de los utensilios, sobre todo si el retoque se da en la parte distal del mismo (Tixier, 1984; Bar Yosef \& Kuhn, 1999).

Sin embargo, la producción de soportes laminares a partir de núcleos prismáticos presenta dos grandes inconvenientes. El primero de ellos es que cualquier error que se cometa durante el proceso de débitage puede resultar fatal para el buen desarrollo del mismo. Así por ejemplo, accidentes de talla como el reflejado o el sobrepasado pueden acabar con las condiciones óptimas de débitage de la tabla del núcleo. El segundo gran inconveniente es que no se puede realizar este tipo de esquemas operativos en materias primas de grano grueso, ya que las características intrínsecas a este tipo de débitage: soportes alargados, de espesor moderado, empleo en algún caso de percusión blanda, etc, así lo aconseja.

Recientemente, la producción laminar ha tomado gran importancia en el debate sobre la transición Paleolítico medio-superior en la región cantábrica a partir de su reconocimiento en la cueva de El Castillo (Cabrera et alli, 2000b). En este trabajo queremos dar a conocer un pequeño conjunto de piezas que pueden ser adscritas a este tipo de esquemas operativos en cueva Morin y que confirman y respaldan los ya descritos en el anteriormente citado yacimiento.

\section{LA CUESTIÓN LAMINAR EN EL PALEOLÍTICO MEDIO}

La producción de soportes alargados es ya conocida desde finales del Pleistoceno medio (EIO 8-6) concebida a partir de métodos Levallois recurrentes (unipolares y bipolares) y esquemas similares al Paleolítico Superior en Inglaterra, el norte de Francia y Bélgica (Révillion, 1994). En Próximo Oriente, es conocido desde hace 150.000 años en tecnocomplejos como el Amudiense o el Pre-auriñaciense (Meignen, 1994), ya con esquemas de producción que recuerdan a los del Paleolítico Superior. Por tanto, la distribución del fenómeno laminar es bastante amplia, documentándose desde la Península Ibérica hasta Ucrania y el Próximo Oriente. En esta última región, junto al norte de Francia, Alemania y Bélgica, es donde mayor número de yacimientos encontramos con este tipo de producción (figura 1).

Dos son las fases propuestas para este fenómeno en el Oeste de Europa: una antigua y otra reciente (Révillion, 1994). La más antigua com- 


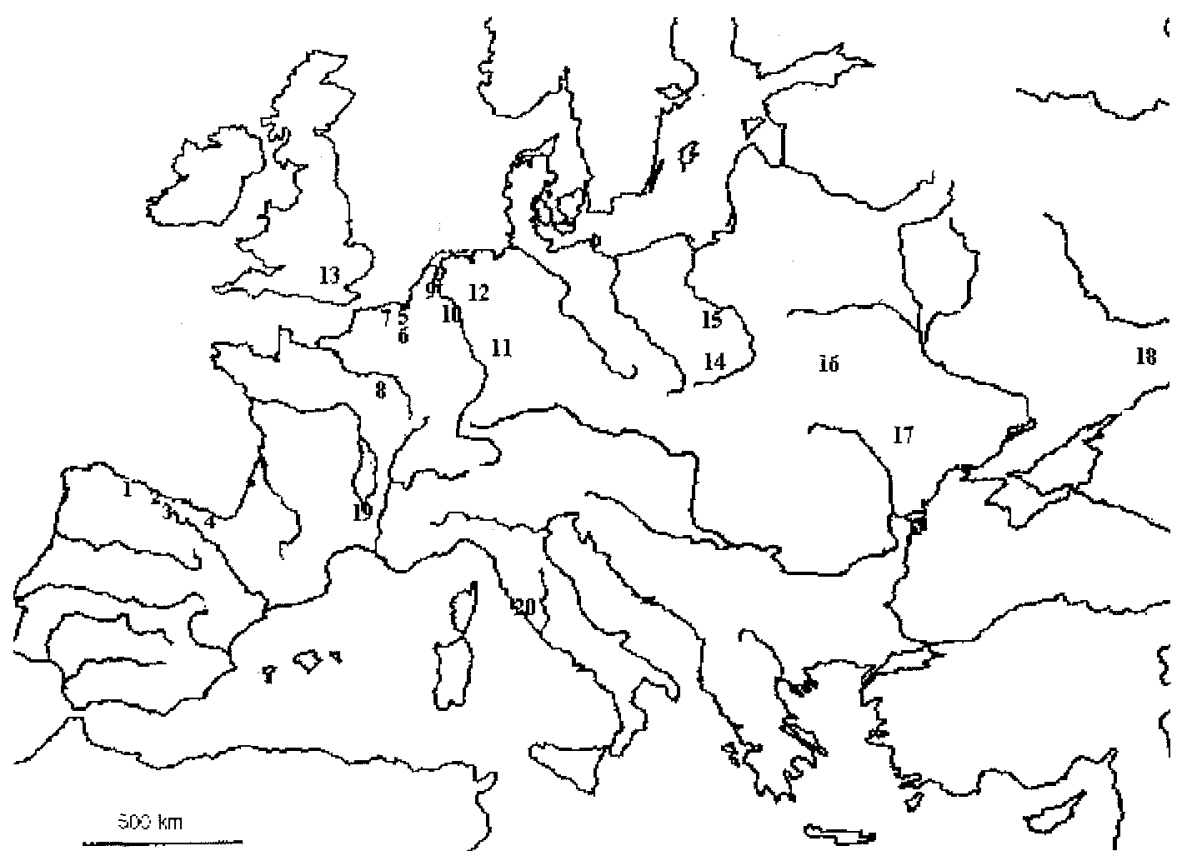

Fig. 1. Relación de yacimientos europeos con industria laminar del Paleolítico Medio más relevantes citados en el texto: 1. La Viña; 2. El Castillo; 3. Cueva Morin; 4. Lezetxiki; 5. Seclin; 6. St. Germain-des-Vaux/Port-Racine; 8. Vinneuf; 9. Le Rissori; 10. Rocourt; 11. Tönchesberg; 12. Rheindalhen; 13. Crayford; 14. Ksiecia Josefa Street; 15. Piekary; 16. Korolevo; 17. Molodova; 18. Chrolodnaja; 19. Champ Grand; 20. Grotta Breuil-Grotta Capriolo.

prendida entre el EOI8 y el EOI6 en yacimientos como Coquelles, Crayford, St-Valéry-sur-Somme, Rissori (Révillion, 1994) o Rocourt (figura 2; Otte et alli, 1990; Otte, 1994), estaría caracterizada en Francia e Inglaterra por la realización de hojas mediante débitage directo, no Levallois, aprovechando, en muchas ocasiones, la morfología inicial del nódulo. La secuencia comenzaría a partir de una hoja de tipo entame, aunque en otros yacimientos, como Rissori, se realizarán a partir de láminas de cresta (Locht, 1990; Révillion, 1994). Este tipo de producción no representa un papel importante en los conjuntos líticos. La fase reciente (EIO 5 y 4) se desarrolla en un amplio marco geográfico en yacimientos como Seclin (Révillion \& Tuffreau, 1994), Saint-Germain-des-Vaux/Port Racine (Révillion \& Cliquet, 1994), Riencourt-lès-Bapaume (ver figura 2, Ameloot-Van der Heijden, 1994), Champ Grand (ver figura 3, Slimak, 1999), etc. en donde la producción laminar se ve acentuada por esquemas 

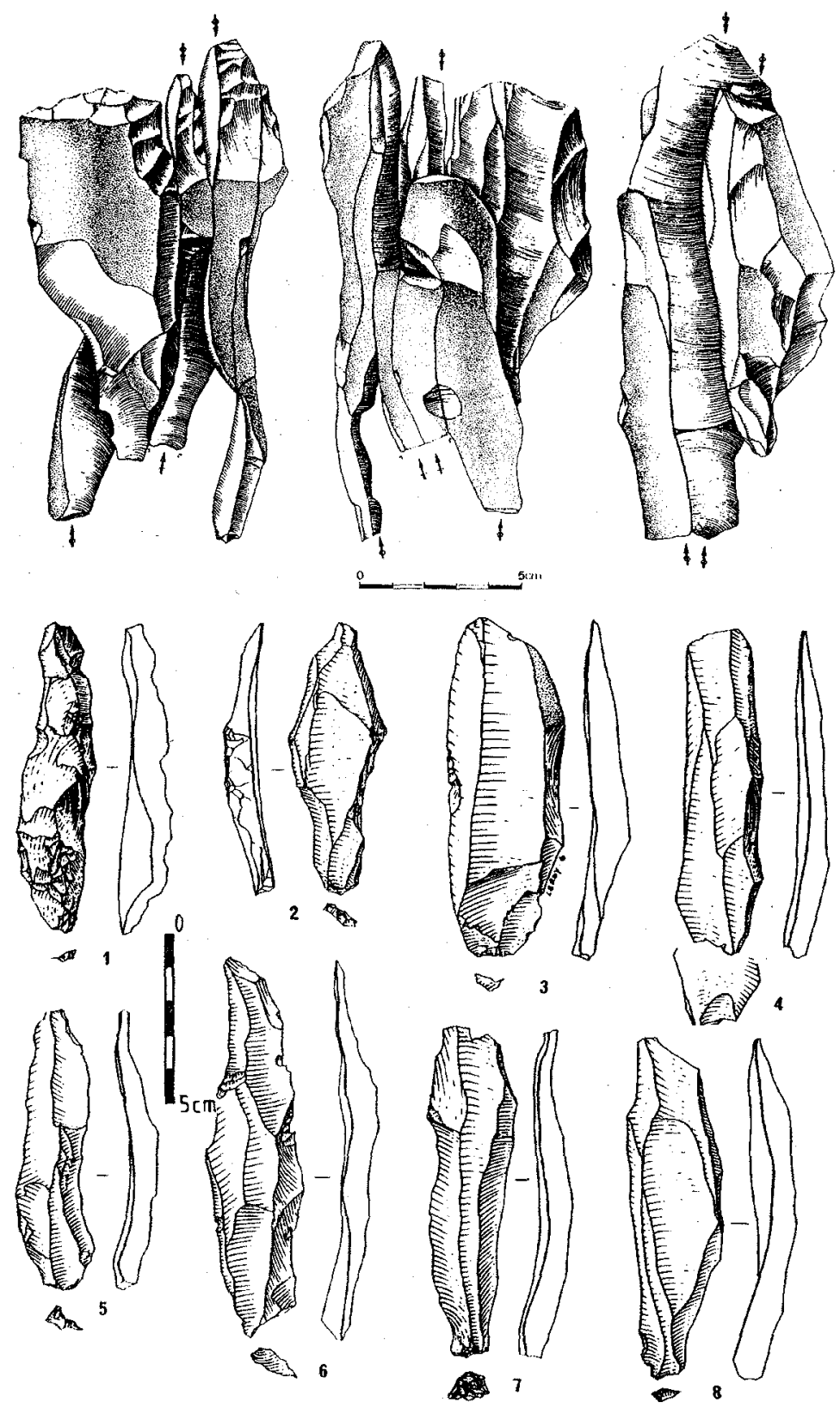

Fig. 2. Núcleo laminar de Rocourt (según Otte, 1994); 1-8: hojas de Riencourt-lès-Bapaume (según Ameloot-van der Heijden, 1994). 

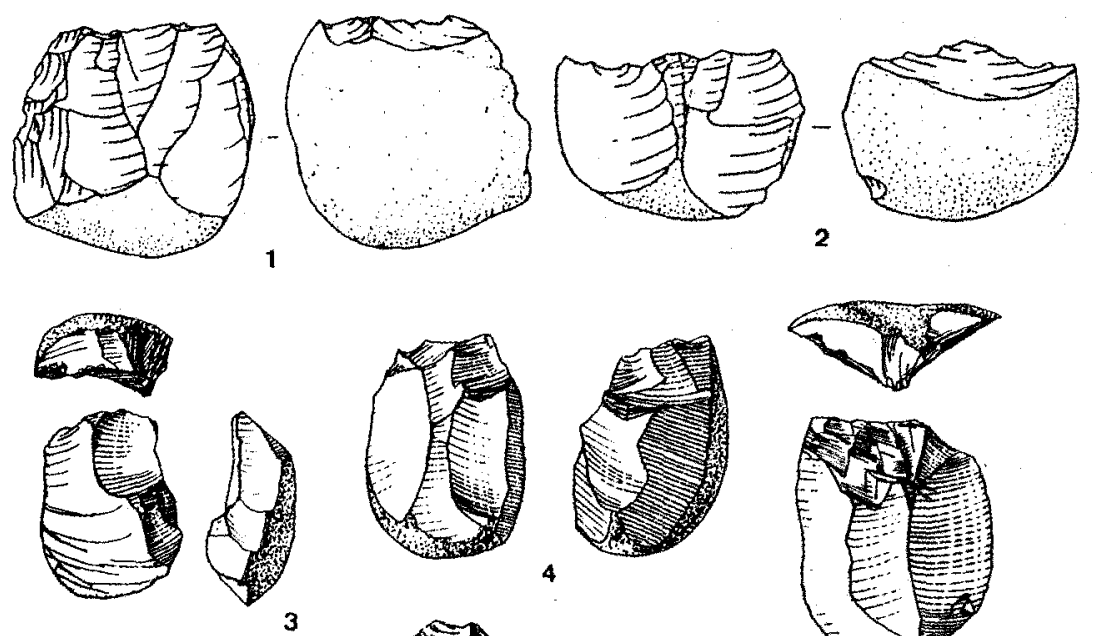

3
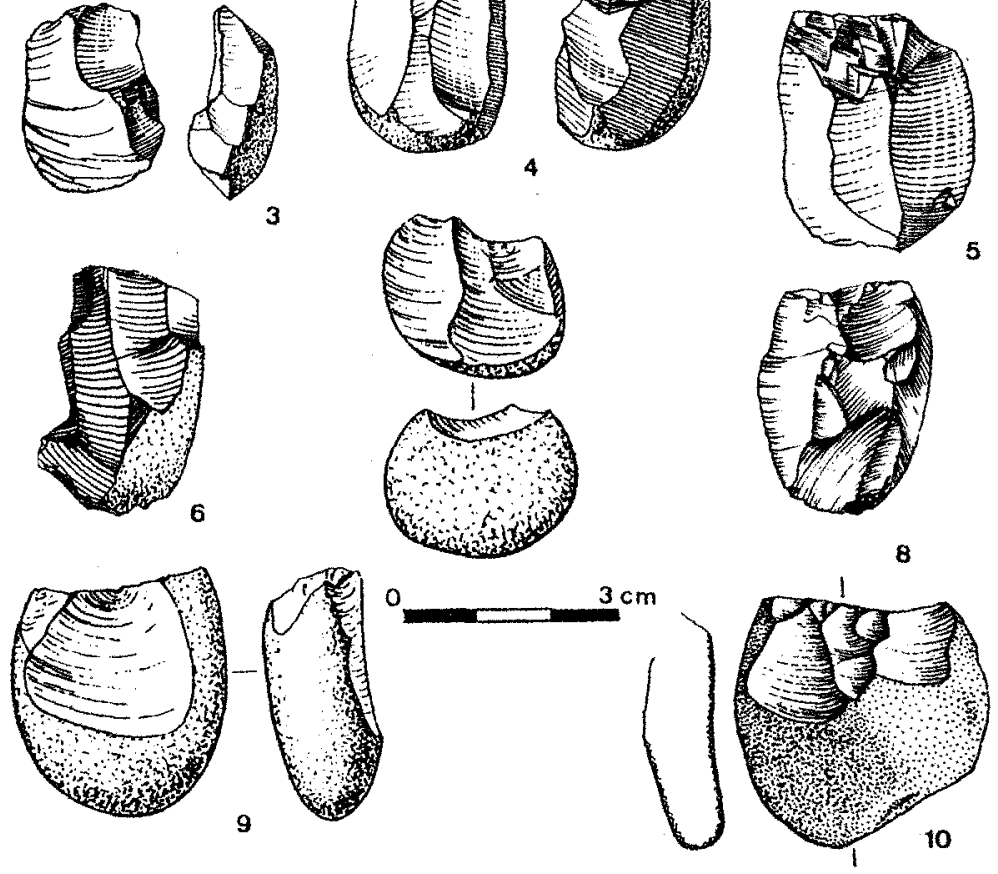

8

Fig. 3. Núcleos de Grotte Breuil (1-6, 8) y Grotte di Sant'Agostino (10), según Kuhn, 1995).

más próximos a los del Paleolítico Superior. Las hojas u hojitas se obtienen a partir de núcleos no Levallois de explotación semienvolvente o envolvente $^{2}$ (éstos últimos en menor número). El débitage, que puede ser iniciado mediante una lámina de cresta, presenta recurrencia y entreteni-

2 Estos dos términos envolvente y semienvolvente corresponden a la traducción que nosotros realizamos para los términos tournant y semi-tournant. 
miento del núcleo (semitabletas) durante el proceso de explotación. Como en la fase anterior, no supone un componente esencial en la producción, existiendo una gran diversidad en los esquemas empleados y en la utilización de los soportes.

En Próximo Oriente es donde existe el otro foco importante de débitage laminar. Como ya comentamos, es conocido antes del EOI 4 en el norte y centro de Levante (Siria, Líbano e Israel) con industrias como el Amudiense, el Preauriñaciense y el Hummaliense. En esta fase más antigua, la explotación de los núcleos es muy similar al modelo de tipo Paleolítico Superior y el peso de los soportes es mayor en el conjunto de la producción lítica. En el Amudiense y el Preauriñaciense existe una separación entre la producción de lascas y de hojas. En el Amudiense (yacimientos de Tabun y Zumoffen) las hojas son estrechas, espesas de sección y con talones lisos. La técnica es la percusión directa con percutor duro. El Preauriñaciense (denominación dada por $F$. Bordes al pensar que era el origen del Auriñaciense) se caracteriza porque las hojas son muy abundantes en el conjunto (llam $=47.9$ ), el débitage no es de tipo Levallois, presentando alguna lámina de cresta y el utillaje retocado representa, mayoritariamente, tipos del grupo Paleolítico Superior (IIless = 45), destacando los raspadores y los buriles. Por otro lado, en el Hummaliense (yacimiento de Hummal) la producción es más exclusiva. Los talones son lisos y la técnica es la percusión directa con percutor duro. El esquema operativo es a partir de núcleos de morfología prismática con explotación uni o bipolar y, aunque el inicio del débitage más común es a partir de hojas de entame, algunos de ellos presentan láminas de cresta. La concepción de débitage del núcleo es en volumen (Boëda, 1990). Los útiles retocados más característicos son los cuchillos de dorso retocados y las puntas hummalienses.

En un momento posterior, la producción de hojas corresponde a criterios de tipo Levallois con hojas subcuadrangulares, subtriangulares, etc. en yacimientos como Tabun IX, donde representan el $76 \%$ de los soportes, aunque son introducidas ya talladas en el yacimiento. Los métodos son recurrentes de extracción convergentes o uni/bipolares. El utillaje retocado no es muy importante, pero destaca en él los tipos del Paleolítico Superior. Aunque existen yacimientos como Douara, Ain Difla o Rosh ein Mor en donde encontramos numerosos núcleos de tipo prismático «sin preparación» y piramidales. Al final del Paleolítico medio cabe destacar el yacimiento de Boker Tachtit cuyo nivel 1 (47-45.000 B.P.) presenta un débitage en volumen con mise en place a partir de aristas, con dos planos de percusión y en el último estadio se extrae una punta Levallois. La superficie explotada es estrecha y los flancos están preparados. El nivel 4 ( \pm 38.000 B.P.) presenta núcleos piramidales apuntados con un débitage por 
toda la periferia. Los soportes son iguales que los del nivel 1 y se retocan en tipos del Paleolítico Superior (Marks \& Volkman, 1983).

El último foco se localiza en el oriente europeo y Asia Central. En Polonia, en el EOI 5-4 disponemos de algunos yacimientos al aire libre con este tipo de tecnología. El más interesante es Ksiecia Josefa Street cerca de Cracovia. En los niveles superiores encontramos tecnología laminar a partir de núcleos Levallois y de tipo Paleolítico Superior a partir de núcleos prismáticos, explotados en volumen con uno o dos planos de percusión y, en algún caso, crestas postero-laterales (Sitlivy et alli, 1999). EI abrigo de Piekary sería el otro yacimiento más significativo con núcleos explotados en volumen con cresta de núcleo para iniciar el débitage (Sitlivy et alli, 1999; Kozlowski, 2001). En Ucrania (Crimea, Dnestr y el área Transcarpiana) aparecen hojas en cantidades significativas en yacimientos como Kabazi, Sajtan-Koba, Cholodjana Blaka, Molodova o Korolevo. Al oeste de Crimea se puede rastrear una evolución de esquemas Levallois a protoprismáticos (Cabaj \& Sittivyj, 1994). En Tadzhikistán encontramos una tradición de industrias de hojas desde el penúltimo interpleniglacial y el débitage a partir de núcleos prismáticos desde los inicios del último glacial en el yacimiento de Khonako III. En momentos posteriores se localizan industrias laminares bajo métodos Levallois y prismáticos unipolares y bipolares en niveles transicionales entre el Paleolítico medio y superior como ocurre en yacimientos como Kul'bulak u Obi-Rakhmat (Schäfer \& Ranov, 1998). Algo similar ocurre en la cercana región de Altaï, en donde destaca el yacimiento de Kara-Bom con niveles comprendidos entre el 62.200 B.P. y el 30.990 B.P. donde se observa una explotación del núcleo desde modos del Paleolítico superior a partir del método Levallois al desplazar el inicio de la explotación al lateral del núcleo (Dérévianko et alli, 1998). Fenómenos similares se aprecian también en yacimientos como Denisova, Ust Karakol o Malaya Sya, que además presenta industria ósea (Otte \& Dérévianko, 2000); o en la vecina república de Kazajstan (Otte et alli, 2000), lo que ha llevado a estos investigadores a plantear la hipótesis de una transición hacia el Paleolítico superior a partir del Paleolítico medio local.

Resumiendo lo hasta ahora visto, debemos destacar la heterogeneidad del fenómeno laminar. Por tanto, no se puede plantear una evolución entre las diferentes industrias porque son abandonadas y retomadas intermitentemente a lo largo del tiempo, por lo que no pueden tener un valor cronológico (Revillion, 1994). Identificar la finalidad de los soportes resulta también una tarea ardua. En la fase antigua apenas están retocados en los conjuntos europeos, mientras que en Próximo Oriente se confeccionan puntas y otros utensilios. En la fase moderna encontramos el mismo 
problema, yacimientos con soportes sin retocar (St. Germain) y yacimientos con soportes retocados en tipos del Paleolítico Superior (Riencourtles-Bapame, Boker Tachtit, etc...). Es por ello, por lo que algunos autores proponen (Revillion, 1994) que este tipo de débitage, al correlacionarse con otros esquemas como el Levallois, el de productos bifaciales, etc, estaría relacionado con necesidades precisas dentro de un amplio abanico de posibilidades ligadas también a un amplio conocimiento tecnológico de los diferentes grupos humanos. Lo que sin duda termina con el papel evolutivo de este tipo de producciones.

\section{EL PAPEL DEL DÉBITAGE LAMINAR EN LA TRANSICIÓN PALEOLITICO MEDIO-SUPERIOR EN EUROPA}

El fenómeno laminar es muy constante en estos momentos del Paleolítico en Europa en diferentes conjuntos industriales, destacando el Chatelperroniense como el principal, en la que el débitage laminar es característico. Pero no debemos olvidar los diferentes grupos industriales de Centroeuropa en donde encontramos, en mayor o menor medida, este tipo de débitage como ocurre en el Szeletiense, el Bryndzeniense (Kozlowsky, 2000) o el Bohuciense (Škrdla, 1996), el Musteriense de Italia (Kuhn,1995, 1996; Kuhn \& Bietti, 2000; Bietti \& Grimaldi, 1996), o el Auriñaciense de Transición en la Peninsula Ibérica (Cabrera et alli, 2001).

El Chatelperroniense definido tecnológicamente a partir de yacimientos como Roc-de-Combe, La Côte (Pelegrin, 1995), Arcy-sur-Cure (Bodu, 1990, Gouedo, 1990) o Saint-Césaire (Guilbaud, 1993) se caracteriza por un débitage de morfología prismática de explotación bipolar, aunque el segundo plano sería de entretenimiento de la tabla y no de explotación neta. El núcleo se configura a partir de aristas laterales y el débitage se inicia con lámina de cresta. Los núcleos se explotan de forma mayoritaria por su cara ancha. Existe el entretenimiento del plano de percusión mediante tabletas de núcleo. Estaría relacionado con el Musteriense de Tradición Achelense de tipo B, del que derivaría (Bordes, 1981; Pelegrin, 1990). Su extensión geográfica abarca el suroeste de Francia y la cornisa cantábrica, aunque en esta última región no es muy abundante, destacando Morin 10 y Labeko Koba IX como yacimientos más característicos (González Echegaray, 1971; Arrizabalaga, 2000).

En Centroeuropa encontramos una serie de tecnocomplejos enraizados con el Paleolítico Medio local y que desarrollan, en mayor o menor medida, una tecnología laminar. Éstos han sido divididos en varios grupos dependiendo del tipo de Paleolítico Medio del que derivan (Kozlowsky, 
2000): 1) Tendencia evolutiva basada en tecnología Levallois. Este es el caso del nivel VI de Temnata, Korolevo II (nivel 2) y Korolevo I (nivel I) en donde, junto a esquemas de tipo Levallois y/o discoides, encontramos una producción de tipo prismático de explotación bipolar con láminas de cresta para el inicio del débitage, en algunos casos muy enraizada la una con la otra como en el Bohuciense (Škrdla, 1996). 2) Tendencia evolutiva a partir de útiles bifaciales. Se encuadrarían aquí tecnocomplejos como el Szeletiense, en cuyo yacimiento epónimo (Szeleta) datado en 41.700 B.P. destacan los núcleos prismáticos y las hojas $(53,8 \%)$, así como la explotación de hojitas en Vendrovice $V$ a partir de núcleos prismáticos sin preparación, que en su fase final pasan a esferoides. En Moldavia, encontramos el Bryndzeniense, aunque con algunos yacimientos excavados desde muy temprana fecha, presenta puntas foliáceas asociadas a la producción laminar usando métodos Levallois, perdurando ésta hasta el 40.000 B.P. en yacimientos como Molodova $\mathrm{V}$ (nivel $\mathrm{Xa}$ ).

En Italia, concretamente en el Latium (en yacimientos como Grotta Breuil o Monte Circeo), el Musteriense final presenta una industria con alta laminaridad (Kuhn, 1995; Kuhn \& Bietti, 2000). Tallados a partir de pequeños cantos de silex mediante una explotación laminar a partir de núcleos uni o bipolares en yacimientos como Grotta Breuil (niveles 3-6) datado en 33.000 B.P. o Grotta Capriolo (figura 4).

En la Península Ibérica también tenemos el Auriñaciense de Transición, el cual sería otra de estas industrias transicionales. Se documenta en el yacimiento de El Castillo (Cantabria), datado en 40.000 B.P. para el nivel $18 \mathrm{c}$ y 38.500 B.P. para el $18 \mathrm{~b}$ (Cabrera et alli, 1989, 1996). Su industria lítica se caracteriza por esquemas operativos de lascas del tipo Levallois recurrente centrípeto y discoides, junto a otros laminares de hojitas de gestión unipolar realizadas en cuarcita y silex (Cabrera et alli, 1996, 2000a, 2001). Su filiación con el Auriñaciense local vendría dada, no solo por la tecnología lítica, sino por la composición tipológica, eminentemente Aurinaciense sobre soportes discoides, la industria ósea (azagayas, cinceles...) y la aparición de arte figurativo, mueble.

\section{CUEVA MORIN}

Situada en Villanueva de Villaescusa, también es denominada en alguna bibliografía como Mazo Moril o cueva del Rey (en alusión a la visita de Alfonso XIII al yacimiento). Se encuadra en una pequeña colina de calizas del complejo urgoniano (posiblemente aptense) dentro de la cuenca de drenaje del Solía, a sesenta metros sobre el nivel del mar y a seis kilóme- 

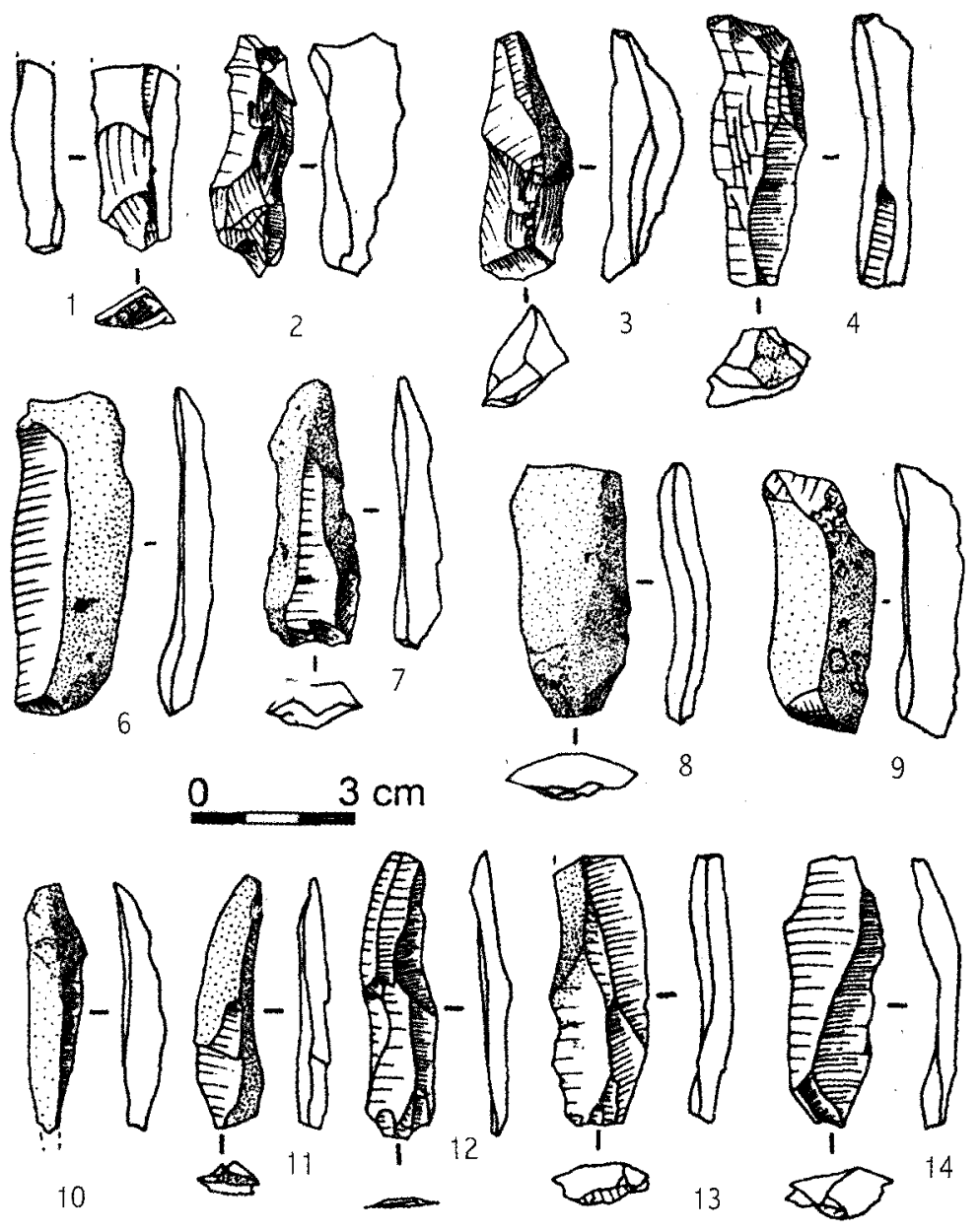

Fig. 4. Hojitas de Champ Grand, Francia (según Slimak, 2000).

tros de la actual línea de costa. La cueva está orientada al NW, continuando en dirección SE para finalizar hacia el SW (figura 5). La altura de la boca es de dos metros (González Echegaray \& Freeman, 1971).

La cueva fue descubierta para la Prehistoria por $\mathrm{H}$. Obermaier y $\mathrm{P}$. Wermet en 1910. Dos años más tarde, en 1912, J. Carballo (fundador y primer director del Museo de Prehistoria y Arqueología de Cantabria) y P. Sierra realizan un pequeño sondeo que permanecerá inédito. $O$. Cendrero 


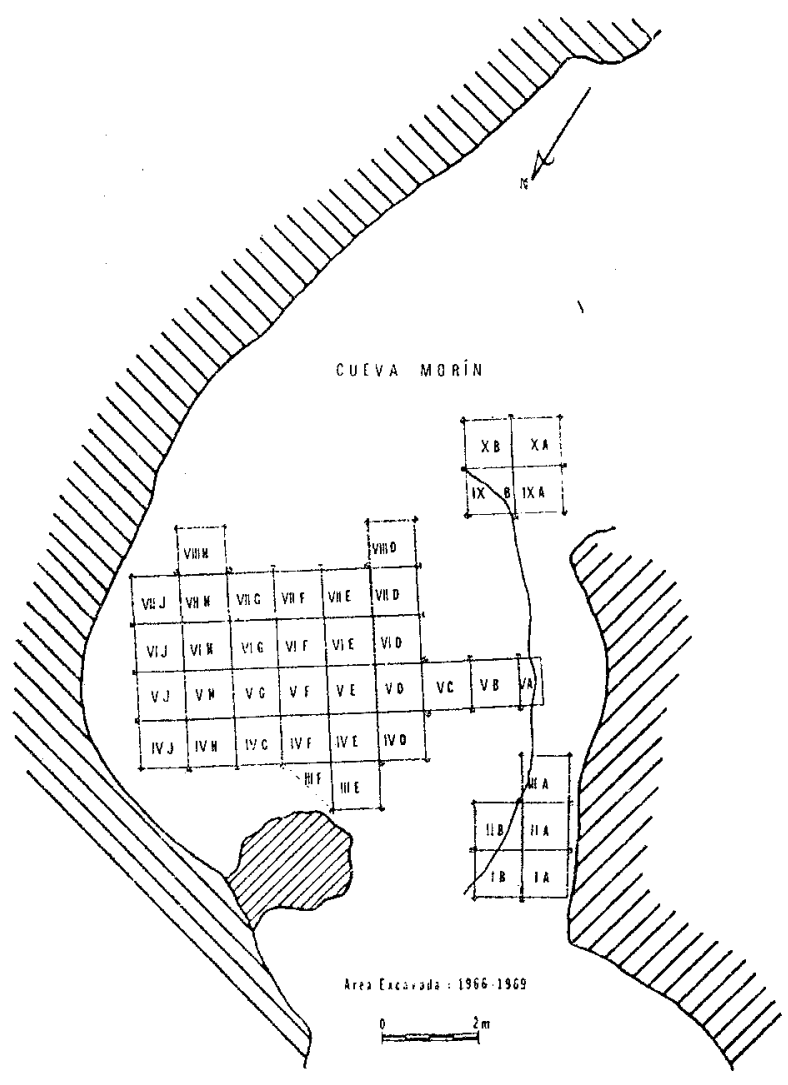

Fig. 5. Plano de Cueva Morin (según González Echeraray, 1973).

publicaría algunos materiales extraídos de la cata dejada por los anteriores investigadores (Cendrero, 1915). Entre 1917 y 1919, J. Carballo retoma los trabajos en la cueva realizando la primera excavación sobre el yacimiento. Se trataba de una cata de diez por dos metros y con una profundidad de dos metros. Con este trabajo se pusieron en evidencia los niveles correspondientes al Paleolítico Superior, así como dos niveles del Paleolítico Medio (Carballo, 1923). En 1918, J. Carballo invita al Conde de la Vega del Sella a excavar el yacimiento tras la finalización de la campaña del primero. Éstas duraron hasta 1920 y fueron muy rápidamente mostradas a la comunidad científica (Vega del Sella, 1921). En 1966 comienza la última intervención arqueológica en la cueva, que duraría hasta 1969. Estaba compuesta por un equipo hispano-estadounidense dirigido por J. González Echegaray y L. G. Freeman (González 
Echegaray \& Freeman, 1971, 1973, 1978). Esta intervención aportó a la Prehistoria española dos aspectos relevantes. Por un lado, la metodología adecuada para las excavaciones modernas y, por otro, la aparición de la primera secuencia completa moderna en Cantabria de la Transición Paleolítico Medio-Superior, la aparición de un nivel Chatelperroniense y, por tanto, la solución al debate sobre el auriñaco-musteriense (González Echegaray, 1969).

La secuencia estratigráfica puesta en evidencia tras esta intervención está compuesta por 22 niveles, cuyas atribuciones culturales son las siguientes:

Nivel 1: Aziliense.

Nivel 2: Magdaleniense.

Nivel 3: Solutrense superior.

Niveles 4 y 5b: Gravetiense.

Nivel 5a: Auriñaciense evolucionado.

Niveles 6 y 7: Auriñaciense típico.

Niveles 8 y 9: Auriñaciense arcaico.

Nivel 10: Chatelperroniense.

Niveles 11-17: Musterienses.

Niveles 18-21: estériles.

Nivel 22: Musteriense.

\section{ESQUEMAS OPERATIVOS LAMINARES (NIVELES 11 Y 12)}

\subsection{Estado de la colección}

El estudio de los últimos niveles musterienses (11 y 12) se halla mutilado en relación con otros estudios y revisiones de los mismos (González Echegaray \& Freeman, 1971, 1973; Sarabia, 1999). Esto es debido a que, a causa de los avatares y abandono que han sufrido las colecciones del Museo de Prehistoria y Arqueología de Cantabria hasta hace unos años, parte de la industria lítica de estos niveles ha desaparecido o bien carece de referencia estratigráfica. Por lo que, el sesgo de nuestro estudio es obvio y nuestros resultados deben ser tomados de manera cualitativa. Sin embargo, la colección ya está suficientemente estudiada de manera cuantitativa (Freeman, 1971, 1973) como para poder apoyarnos en dichos trabajos y complementar así aquellas carencias que encontramos en la serie por nosotros estudiada. Las diferencias entre la colección completa y la estudiada por nosotros se puede comparar en el cuadro 1. 
Cuadro 1. Inventario del material estudiado de Morin 11 y 12

\begin{tabular}{lcccr}
\hline & $\begin{array}{c}\text { Nivel 11 } \\
\text { (Freeman, 1973) }\end{array}$ & Nivel 11 (2001) & $\begin{array}{c}\text { Nivel 12 } \\
\text { (Freeman, 1973) }\end{array}$ & Nivel 12 (2001) \\
\hline Retocado & 226 & 76 & 316 & 104 \\
No retocado & 383 & 130 & 291 & 82 \\
Debris & 1.063 & 243 & 1.250 & 102 \\
Canto/percutor & 5 & 4 & 12 & 2 \\
Tectoclasto & & 7 & & 4 \\
Total & 1.677 & 460 & 1.869 & 294 \\
\hline
\end{tabular}

\subsection{Descripción de los niveles}

Ambos niveles están formados por arenas con limos que originalmente eran de color pardo claro. La aparición de parte de un hogar (destruido en anteriores intervenciones del yacimiento) en el nivel 11 cambió esta situación al alterar el sedimento. Así el techo del nivel 12 presenta un color más claro debido a la rubefacción del mismo. La deposición de éstos se produjo bajo condiciones ambientales uniformes de carácter templado (Butzer, 1971, 1973; Laville \& Hoyos, 1994). El análisis polínico revela la presencia de un paisaje de pinar con abundancia de helechos y gramíneas datándose en el interestadial Hengelo (Leroi-Gourhan, 1971).

La muestra corresponde a una pequeña área dentro de la cueva (cuadros VA y VB) no correspondiendo su superficie total a más de $1 \mathrm{~m}^{2}$. Sin embargo, resultaron muy ricos en cuanto al número de restos encontrados. Estos niveles presentan gran diversidad en cuanto a la cantidad de materias primas representadas, destacando el sílex, junto a otras como son la cuarcita, la ofita, la arenisca, etc. La industria realizada en sílex presenta un gran número de piezas con alteraciones de tipo térmico, esto es también confirmado, en parte, por nuestro estudio, ya que en nivel 11 el 62,3 $\%$ del silex presenta este tipo de alteraciones, mientras que en el 11 sólo

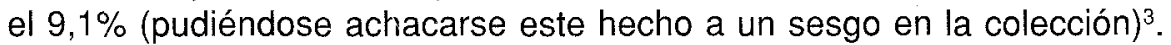
Tipológicamente correspondería a un Musteriense de denticulados (Freeman, 1971, 1973). El débitage de lascas se encuadra básicamente dentro de esquemas de débitage discoide, aunque podrían estar presentes en bajo número otros métodos como el Levallois en variedades recurrentes (figura 6 y 8 ).

\footnotetext{
3 Incluimos como alteraciones térmicas el aporcelanado, los levantamientos térmicos y el cuarteado. En cuanto a la materia prima sólo incluimos el silex pues es donde mejor caracterizados están este tipo de fenómenos.
} 

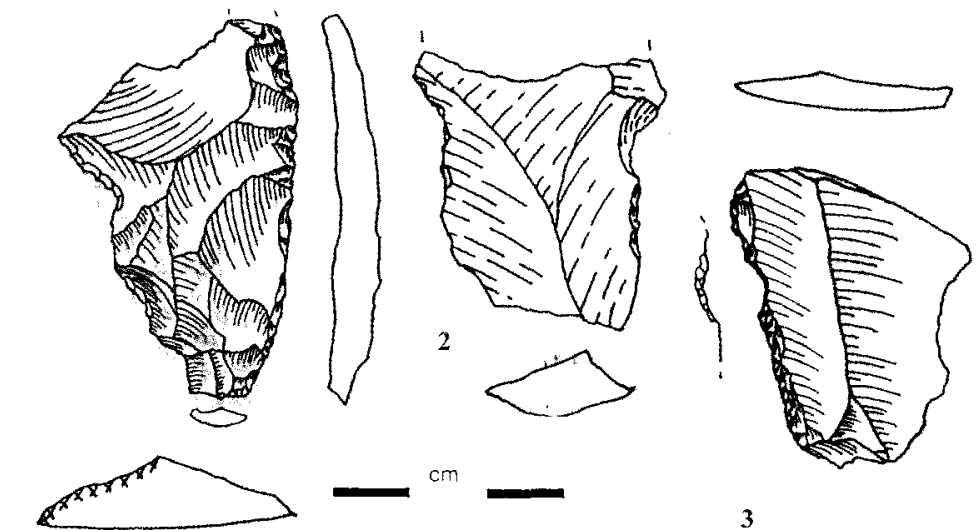

3
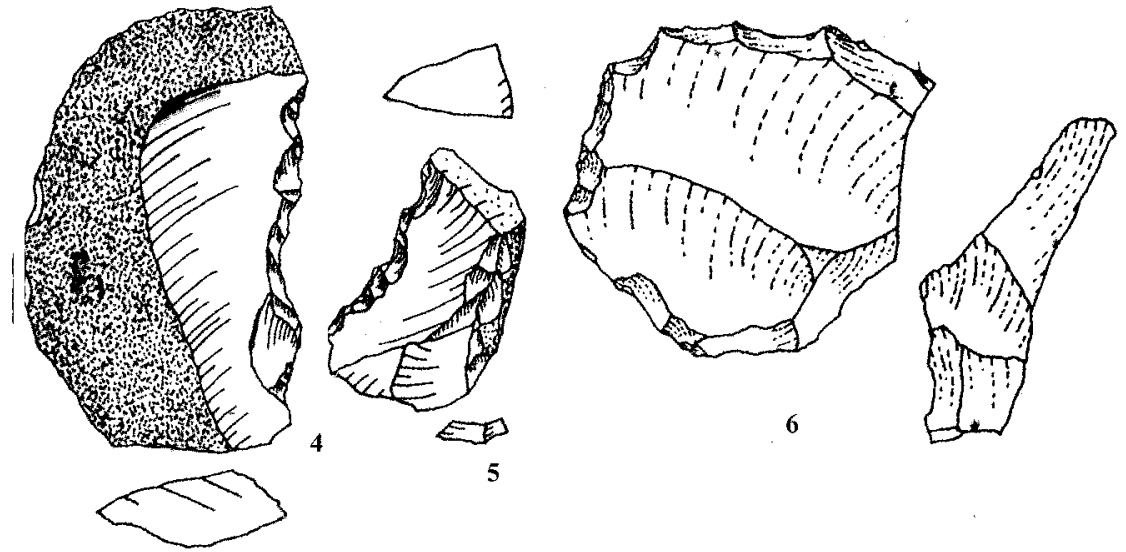

Fig. 6. Material retocado del nivel 11 de cueva Morin (dibujos J. M. Maillo).

\subsection{Evidencia empírica}

El conjunto de piezas asignables a este tipo de esquemas operativos es muy exiguo, no debiendo ser muy importante a escala cuantitativa dentro del total del conjunto lítico. Es por ello, por lo que preferimos presentar en conjunto ambos niveles.

a) Los núcleos: Disponemos de cuatro núcleos que presentan negativos de extracciones de hojitas o lasquitas laminares en ambos niveles (dos para el nivel 11 y dos para el 12). La materia prima está compuesta por sílex, excepto un núcleo sobre cuarcita de grano fino. Morfológicamente, se pueden clasificar, grosso modo, como núcleos de tendencia prismática y de 
explotación unipolar. Están confeccionados a partir de lascas o cantos de pequeño tamaño (no más de cinco centímetros). La mise en forme es aparentemente simple, correspondiendo el inicio de la explotación a una pieza de tipo entame, excepto en uno de los núcleos en donde aparece un negativo de dirección transversal al sentido de la explotación y que podría corresponder a la realización de una lámina de cresta para iniciar la producción o a una neoarista para corregir algún accidente en el desarrollo de la explotación (figura 7.1).

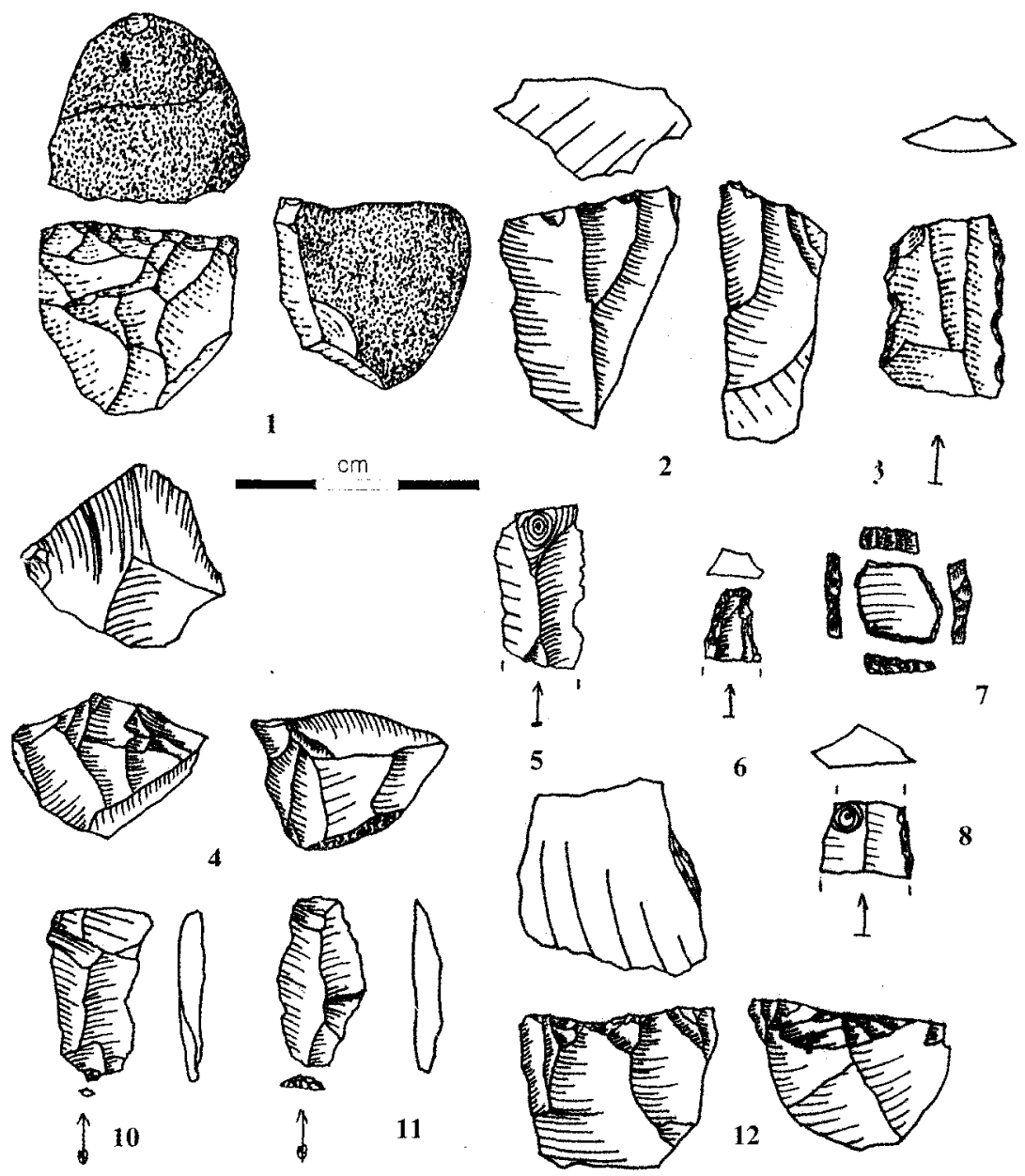

Fig. 7. Material laminar de cueva Morín (nivel 11:4, 10-11; nivel 12: 1-3, 5-8; dibujos J. M. Maíllo). 

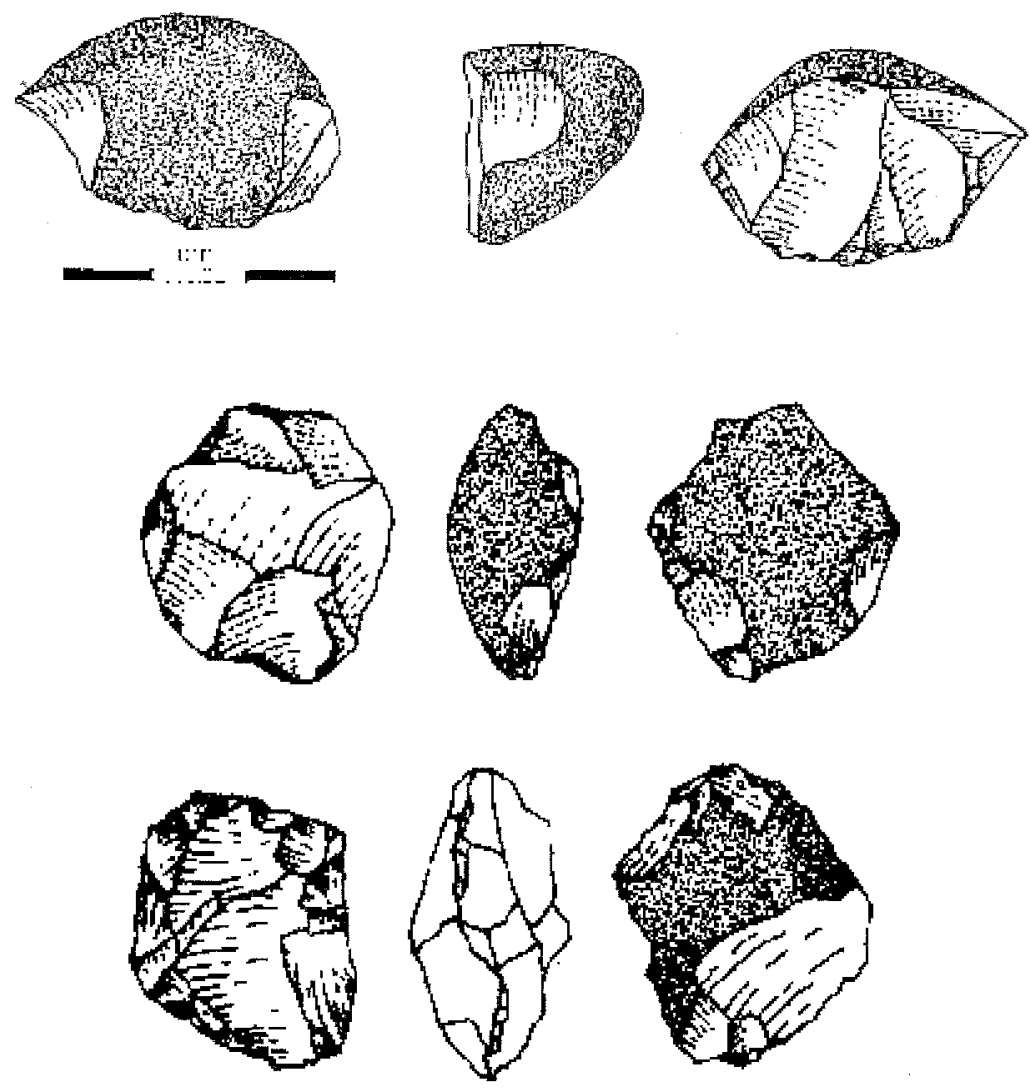

Fig. 8. Núcleo Levallois del nivel 12 de cueva Morín y discoides (dibujo de J. M. Maíllo).

Para los planos de percusión se aprovecha la superficie cortical/natural del soporte o bien la cara bulbar de la lasca-soporte. No tenemos evidencia de la fase de inicio de la explotación, pero como ya se comentaba arriba, ésta puede corresponder a un tipo de hoja-entame o de arista natural. Atendiendo a este modelo debería existir una adecuación morfológica del soporte antes del comienzo de la explotación. Los últimos negativos de la secuencia de extracción reflejan una producción de hojitas en dos de los núcleos (figuras 7.2 y 7.4), en otro de ellos sería muy probable (figura 7.1) y de lasquitas-laminares en el restante (figura 7.12). La explotación sería convergente en tres de los núcleos y paralela en uno.

El desarrollo del débitage presenta dos variantes significativas de ejecución: pueden existir una o dos tablas. En la primera variante, cuando 
sólo existe una tabla, la explotación se realiza de manera unipolar y dirección convergente de los negativos en la zona basal del núcleo. La recurrencia se realiza mediante extracciones de soportes "desbordantes" que reavivan el cintrado de la tabla al efectuarse éstos en la intersección entre la tabla y uno de los flancos. La otra variante es en la que la explotación del núcleo se realiza mediante dos tablas adyacentes. En este caso la explotación converge hacia la arista de unión entre las dos tablas, lo que facilita el control del cintrado. En este caso las extracciones son también de dirección unipolar, pero los negativos son paralelos. El abandono viene condicionado por los numerosos negativos de accidentes de talla observados, que no sólo desdibujan las condiciones morfotécnicas de carenado y cintrado de la tabla, sino que desvirtúan, incluso, la caracterización de este tipo de explotación.

b) Los soportes: como el resto del material presentado, los soportes atribuibles a este tipo de esquemas son escasos. Aquí sí debemos tener en cuenta los avatares sufridos por los materiales en los depósitos del Museo de Prehistoria y Arqueología de Cantabria al desaparecer, en ambos niveles, las piezas de menor tamaño. Contamos con solo cinco piezas atribuibles a estos esquemas técnicos (figura 7.5-11). Todas ellas realizadas sobre silex, no presentando cortex. Tan sólo dos de ellas presentan talón (puntiforme y facetado). Todas presentan nervaduras paralelas, dirección de negativos anteriores paralelos al eje de débitage (Inizan et alli, 1995). Dos de las piezas han sido retocadas: una de ellas presenta un retoque lateral semiabrupto (figura 7.8) y la otra un dorso abrupto (figura 7.6). El modo de percusión sólo puede ser discriminado en los dos soportes que presentan talón. En ambos las características corresponden a las descritas para la percusión directa con percutor blando (Pelegrin, 2000). Sin embargo, no debemos excluir la percusión directa con percutor duro para la extracción de alguno de los soportes tras el estudio de los negativos de los núcleos.

Debemos constatar la escasa estandarización de los núcleos de este tipo de explotación, así como la variabilidad dentro de la tendencia prismática general. Sin embargo, la disposición en volumen del núcleo a explotar, así como las modalidades de preparación y explotación los hace alejarse de concepciones de tipo Levallois o discoide y los acerca a algunas modalidades de débitage laminar que vamos a encontrar en el Auriñaciense arcaico (Maíllo Fernández; e.p.), pero, sobre todo, nos acercan a los esquemas desarrollados tanto en el Musteriense final, como en el Auriñaciense de Transición de la cueva de El Castillo (Cabrera et alli, 2000b; 2001). 
El modelo de producción lítica aquí caracterizado debe ser puesto en relación con el resto del conjunto lítico de estos niveles arqueológicos. Esta producción de hojitas debe agruparse en un objetivo más amplio, aunque no numeroso, de obtención de ciertos soportes alargados, ya hojas, ya lascas laminares que son obtenidas a partir de otros métodos como pueden ser los Levallois (figuras 7.3 y 8.1) y del que la producción de soportes microlaminares a partir de núcleos de tendencia prismática sería una modalidad paralela para la obtención de dichos soportes. Pero, ¿Cuál puede ser el motivo o la necesidad que obliga a realizar este tipo de soportes? En la región cantábrica es ya casi mítica la idea de que la materia prima condiciona enormemente la producción lítica y, en parte así es. Sin embargo, debemos relativizar esta hipótesis ya que la materia prima únicamente obliga a realizar soportes de tamaño menor al habitual en otras regiones (Bernaldo de Quirós \& Cabrera, 1996), especialmente la región de Dordoña. Además, la región cantábrica aporta una cuarcita de grano muy fino que permite no sólo la producción laminar, sino la elaboración de utensilios de retoque plano durante el solutrense. Esta situación nos obliga a matizar nuestra hipótesis inicial. Entonces, ¿Por qué las hojas? Sin duda, estamos ante una necesidad de los grupos musterienses de esta región por obtener unos soportes de unas dimensiones y una morfología concretas. Por otro lado, no disponemos de análisis traceológicos ni de suficiente evidencia arqueológica como para poder ir más lejos en nuestras hipótesis. Sin embargo, podemos afirmar este tipo de soportes no parecen demasiado importantes a nivel cuantitativo en las necesidades de estos grupos ya que el desarrollo de este tipo de débitage no está muy generalizado ni estandarizado.

\section{EL DÉBITAGE LAMINAR EN EL MUSTERIENSE FINAL CANTÁBRICO}

Además de en Cueva Morin podemos encontrar algunos ejemplos de producción laminar en algunos yacimientos del Musteriense final en la cornisa cantábrica.

a) El Castillo: yacimiento situado en Puente Viesgo (Cantabria) está muy próximo a Morin. En la Unidad 20 (niveles 20 a, b, c, d, e) y Unidad 21 de dicho yacimiento se ha documentado una pequeña, pero interesante muestra de débitage de hojitas y lasquitas laminares (Cabrera et alli, $2000 \mathrm{~b}$ ) con una datación de $43.300 \pm 3800 \mathrm{BP}$ (GiFA 92506) para el nivel $20 b$ (Cabrera et alli, 1996). La materia prima empleada más común es la cuarcita de grano muy fino y de buena calidad para la talla (Cabrera et alli, 
1996) y, en menor cantidad, el silex. La producción se organiza a partir de pequeños nódulos de morfología prismática o tendente a prismática de gestión unipolar y bipolar (ésta más restringida).

La mise en forme es sencilla, comenzando el débitage a partir de hojitas o lasquitas de tipo entame. Como ocurre en cueva Morin existen dos modalidades de organización de este tipo de débitage: una única tabla o dos tablas adyacentes. El reacondicionamiento se realiza a partir de hojitas "desbordantes" semicorticales que abren la tabla de explotación del núcleo ya que se extraen aprovechando la convergencia entre los negativos de la tabla y uno de los flancos del núcleo. Los planos de percusión son corticales o están realizados a partir de grandes extracciones.

La explotación se orienta de forma paralela o convergente en la tabla, siendo su mayoria hojitas y hojitas laminares. La técnica empleada es la percusión directa con percutor duro y blando (figura 9).

1
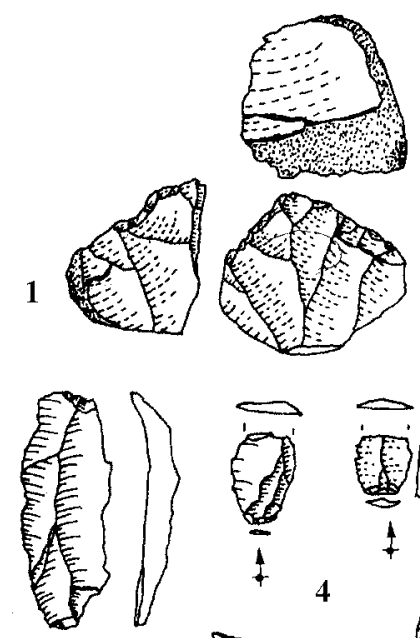

3
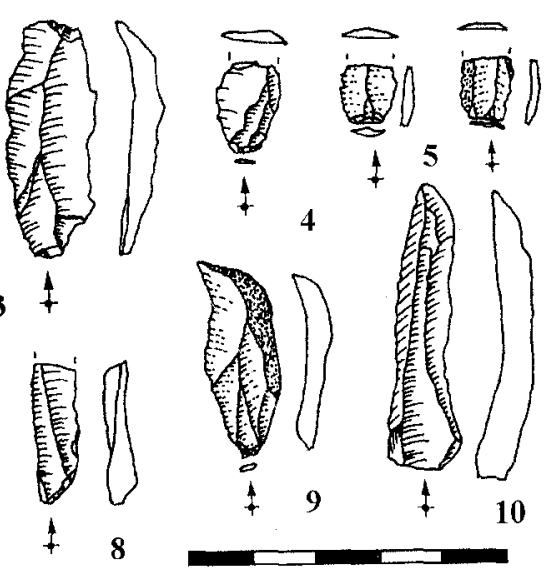

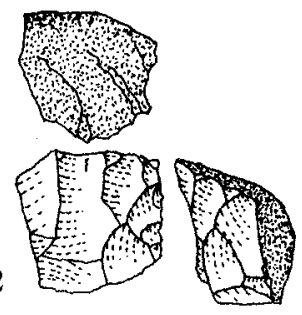

\section{2}
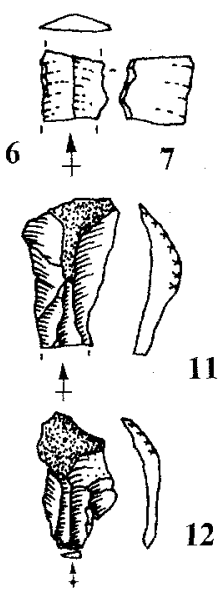

Fig. 9. Núcleos y hojitas de los niveles musterienses de la cueva de El Castillo: 1-2, nivel 20c; 3-6, nivel 20e; 7-12, nivel 21 (según Cabrera et alli, 2000. Dibujos J. M. Maílo). 
b) Lezetxiki: situada en Mondragón (Guipúzcua) fue excavada entre 1956 y 1968 por J. M. de Barandiarán. Presenta ciertas dificultades de interpretación de algunos de sus niveles.

Los niveles que nos interesan son el III, IVa y IVb. Algunos investigadores piensan que todos ellos son Auriñacienses (Esparza, 1993), otros que el III es Auriñaciense (Arrizabalaga, 1995) o presenta alteraciones postdeposicionales (Baldeón, 1993), mientras que los niveles IVa y IVb serían musterienses, aunque para algunos con rasgos transicionales (Arrizabalaga, 1995).

Revisando algunas de las ilustraciones que del material se presentan (Baldeón, 1993: 47, fig 33.5, 6, 7 y 9) podemos observar una serie de raspadores carenados que en otro contexto serían analizados como núcleos de hojitas (figura 10).

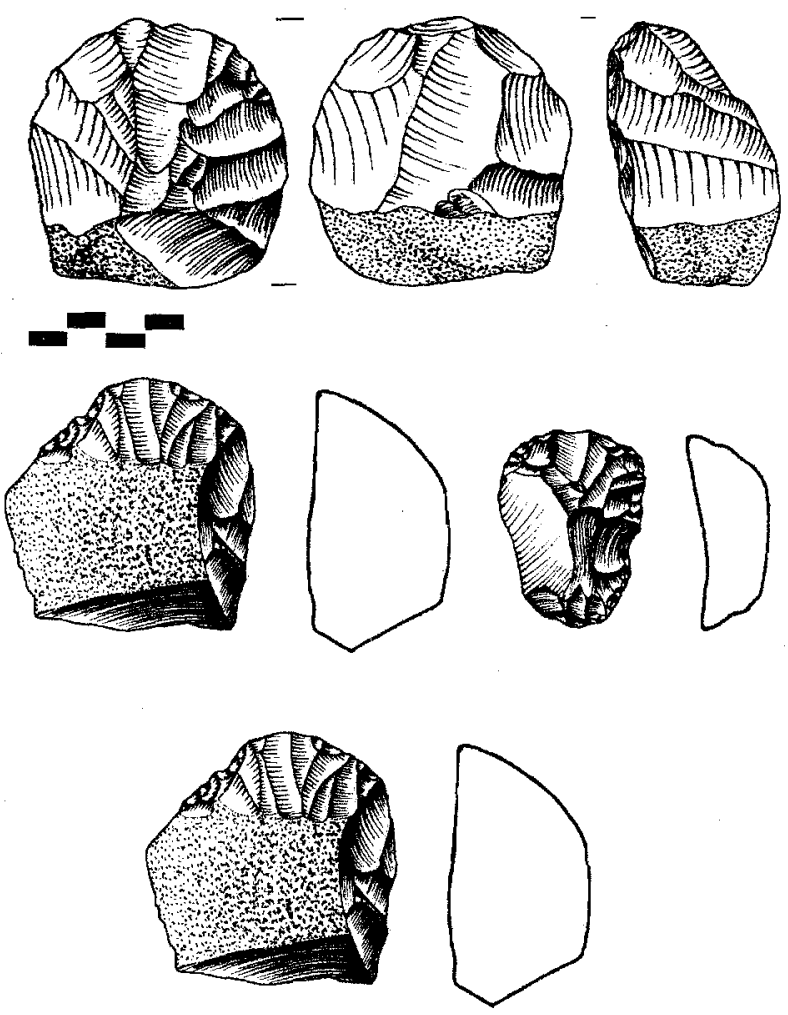

Fig. 10. Carenados del musteriense de Lezetxiki (según de Baldeón, 1993). 
c) La Viña: localizado en Asturias representa uno de los yacimientos más interesantes para estos momentos históricos en la Península Ibérica. Presenta una estratigrafía que comprende varios estratos auriñacienses y musterienses (Fortea, 1995, 1999). Además de poseer uno de los auriñacienses con azagayas de base hendida más antiguos de Europa (nivel XIII, $36.500 \pm 750$ B.P.); sus niveles musterienses representan un «Musteriense final con elementos tecnológicamente evolucionados" (Fortea, 1999: 40). Algunos de ellos, como el XV aporta alguna hojita retocada o el XIV*, datado en $>47.700$ B.P., posee un núcleo de hojitas. Sin embargo, no poseemos más que breves informes sobre las industrias de este yacimiento, pero la importancia que se otorga a los elementos tecnológicos reseñados arriba nos ayuda a pensar en la relevancia de los mismos.

\section{DISCUSIÓN}

Los esquemas operativos de tipo laminar han sido dados a conocer recientemente en la cueva del Castillo (Cabrera Valdés et alli, 2000b) y ahora en Morin presentando aspectos muy similares (además de estar constatado en La Viña y Lezetxiki), lo que nos permite apreciar el fenómeno como un hecho algo más que anecdótico. El débitage está caracterizado básicamente por:

a) Núcleos de morfología prismática o tendente a prismática de gestión unipolar y, en menor medida, bipolar y sólo constatados en El Castillo.

b) La dinámica de explotación se organiza a partir de una única tabla de explotación o de dos adyacentes.

c) La mise en forme es sencilla, comenzando la explotación a partir de hojas entame. El reacondicionamiento se realiza a partir de hojas «desbordantes» laterales que regulan el cintrado de la tabla de explotación. Los planos de percusión se realiza a partir de una gran extracción o se emplea la superficie ya existente en el soporte, zona cortical o cara bulbar de lascado.

d) La explotación está orientada de forma paralela o convergente en la tabla de extracción. Los soportes extraídos corresponden a hojitas y a lasquitas-laminares.

e) La técnica empleada es la percusión directa, bien con percutor duro, bien con blando.

Los esquemas operativos puestos en evidencia en El Castillo y ahora en cueva Morin están muy relacionados con los que más tarde, en el 
Auriñaciense, vamos a encontrar en dichos yacimientos. La adecuación morfométrica del nódulo que va a ser tallado, la mise en forme simple, utilizando hojitas desbordantes para controlar el cintrado de la tabla, la alternancia de técnica empleada, etc, recuerdan los mismos esquemas auriñacienses no sólo de los yacimientos citados, sino de numerosos yacimientos del inicio del mismo. Sin embargo, existen diferencias claras entre ambos conjuntos como puede ser la estandarización en la preparación del núcleo o la recurrencia del débitage, pero que son meramente formales y no afectan a la concepción del mismo.

Existe otro factor por el que estos conjunto de hojitas son importantes y es que refutan la idea de algunos investigadores (Bar-Yosef \& Kuhn, 1999) que arguyen que la verdadera diferencia entre el Paleolítico Medio y el Superior no está en la producción de hojas, sino en la de hojitas y las implicaciones de comportamiento, sobre todo cinegético, subyacentes. Sin entrar en valoraciones funcionales de los conjuntos de hojitas cantábricos (en proceso de realización) consideramos que la hipótesis reseñada más arriba debe ser sometida a una reflexión mas intensa en donde se deben de tener en cuenta más variables que la meramente biológica.

Somos conscientes de que la muestra aquí presentada, así como la de los niveles musterienses de El Castillo, es muy escasa, pero consideramos que debe ser tratada desde un punto de vista cualitativo y no cuantitativo, como en todos los procesos de transición (Cabrera \& Bernaldo de Quirós, 1990). La similitud entre los esquemas laminares en el Musteriense Final y el Auriñaciense resulta significativa, así como la pervivencia de esquemas operativos de concepción discoide en este último periodo. Sin embargo, las valoraciones de estos hechos, ya culturales, ya biológicos deben ser confirmadas por varios campos de investigación de los que la tecnología lítica sólo forma una parte.

\section{Agradecimientos}

Deseo hacer constar mi agradecimiento a las siguientes personas: Federico Bernaldo de Quirós (Univ. de León), Victoria Cabrera (UNED), Laurent Chiotti (Musée de l'abri Pataud), Nati Fuertes (Univ. de León), Emiliano Leoz (Musée de l'abri Pataud) e lluminada Ortega (AFAN) por la discusión y/o lectura de las versiones preeliminares del texto. Al personal del Museo de Prehistoria y Arqueología de Cantabria, especialmente a Amparo Ortiz, por la ayuda y facilidades prestadas en el estudio del material. 


\section{BIBLIOGRAFÍA}

Ameloot-van der Heijden, N. (1994): L'ensemble lithique du niveau CA du gisement de Riencourt-lès-Bapaume (Pas-de-Calais). En Revilion, S. \& Tuffreau, A.: Les industries laminaires au Paléolithique Moyen. Dossier de Documentation Archeologique, 18 : 63-75.

Arrizabalaga, A. (1995): La industria lítica del Paleolítico Superior Inicial en el Oriente Cantábrico. Tesis Doctoral. Univ. Pais Vasco, pág. 1000.

ARRIZABALAGA, A. (2000): Los tecnocomplejos líticos del yacimiento arqueológico de Labeko Koba (Arrasate, país Vasco). En Arrizabalaga \& Altuna (ed): Labeko Koba (País Vasco). Hienas y humanos en el Paleolítico Superior. Munibe, $52: 193-343$.

BALDEón, A. (1993): El yacimiento de Lezetxiki (Guipuzkoa, País Vasco). Los niveles musterienses. Munibe, 45: 3-97.

BAR-YOSEF, O. \& KUHN, S.L. (1999): The big deal about blades: Laminar technologies and Human Evolution. American Anthropologist, 101 (2): 322-338.

Bernaldo de Quirós, F.\& Cabrera, V. (1996): Raw material in the Palaeolithic of Cueva del Castillo and in the Cantabrian Region. En Moloney, N.; Raposo, L. \& Santonja, M. (ed.) Non-flint Stone Tools and the Paleolithic Occupation of the Iberian Peninsula, B.A.R. International Series, 649: 21-32.

BIETTI, A. \& GRIMALDI, S. (1996) : Small flint pebbles and Mousterian reduction chains: The case of Southern Latium (Italy). Quaternaria Nova, VI: 237-259.

Bodu, P. (1990): L'application de la méthode des remontages à l'étude du matériel lithique des premiers niveaux châtelperroniens d'Arcy-sur-Cure. En Farizy, C. (ed.): Paléolithique moyen récent et Paléolithique supérieur ancien en Europe. Mémoires du Musée de Préhistoire d'lle de France, $3: 309-312$.

BOËDA, E. (1990) : De la surface au volumen : analyse des conceptions des débitages Levallois et laminaire. En Farizy, C. (ed.): Paléolithique moyen récent et Paléolithique supérieur ancien en Europe. Mémoires du Musée de Préhistoire d'lle de France, $3: 63-68$.

Bordes, F. (1981): Leçons sur le Paléolithique ; 2 Le Paléolithique en Europe, pág.459.

BUTZER, K. W. (1971): Comunicación preliminar sobre la geología de cueva Morin (Santander). En González Echegaray, J. \& Freeman, L.G. (coord.): Cueva Morin. Publicaciones del Patronato de las cuevas prehistóricas de la provincia de Santander, VI: 345-356.

BUTZER, K. W. (1973): Notas sobre la geomorfología regional de la parte occidental de la provincia de Santander y la estratigrafía de cueva Morin. En González Echegaray, J. \& Freeman, L.G. (coord.): Cueva Morin. Publicaciones del Patronato de las cuevas prehistóricas de la provincia de Santander: $267-276$.

CABAJ, V. \& SitLIYJ, V. (1994): The blade component in the Middle Palaeolithic of Ukraine: origin and evolution. En Revillon, S. \& Tuffreau, A.: Les industries laminaires au Paléolithique Moyen. Dossier de Documentation Archeologique, $18: 161-177$.

CABRERA VALDÉS, V. \& BISChOFF, J. (1989): Accelerator ${ }^{14} \mathrm{C}$ dates for Early Upper Paleolithic (Basal Aurignacian) at El Castillo cave (Spain). Journal of Archaeological Science, 16: 577584.

Cabrera Valdés, V. \& Bernaldo de Quirós, F. (1990): Donnes sur la transition entre le Paléolithique moyen et le Paléolithique supérieur de la région Cantabrique :Révision critique. En Farizy, C. (ed.): Paléolithique moyen récent et Paléolithique supérieur ancien en Europe. Mémoires du Musée de Préhistoire d’lle de France, 3 : 185-189.

Cabrera Valdés, V.; Valladas, H.; Bernaldo de Quirós, F. \& Hoyos, M. (1996): La transition Paléolithique Moyen-Paléolithique Supérieur a El Castillo (Cantabrie): nouvelles datations por le carbone 14. Comptes Rendues de l'Academie des Sciences de Paris, 322 lla: 10931098.

Cabrera Valdés, V.; Lloret, M.; Bepnaldo de Quirós, F. \& Hoyos, M. (1998): El Auriñaciense Arcaico de la cueva del Castillo. En Balbín (ed): I/ Congreso de arqueología Peninsular, tomo l: $133-140$.

Cabrera Valdés, V.; Pike-Tay, A.; Lloret, M. \& Bernaldo de Quirós, F. (2000a): Continuity patterns in the Middle-Upper Palaeolithic Transition in Cantabrian Spain. En Stringer, B.; Barton, R.N.E. \& Finlayson, J.C. (eds.): Neanderthals on the Edge, Oxbow Books: 85-94.

Cabrera Valdés, V.; Maíllo Fernández, J. M. \& Bernaldo de Quirós, F. (2000b): Esquemas operativos laminares en el Musteriense final de la cueva del Castillo (Puente Viesgo, Cantabria). Espacio, Tiempo y Forma, Serie I, 13: 51-78. 
Cabrera Valdés, V.; Maíllo, J. M.; Lloret, M \& Bernaldo de Quirós, F. (2001): La transition vers le paléolithique supérieur dans la grotte du Castillo (Cantabrie, Espagne): la couche 18. LAnthropologie, $105: 505-532$.

Carballo, J. (1923): Excavaciones en la cueva del Rey, en Villanueva (Santander). Junta Superior de Excavaciones y Antigüedades, 9, pág. 40, IX lám.

Cendrero, O. (1915): Resumen de los bastones perforados de la Provincia de Santander. Comisión de Inves. Paleontológicas y Prehistóricas. Notas 1 y 2.

Derevianko, A.; Pétrine, V. \& OtTe, M. (1998) : Variante de la Transition du Moustérien au Paléolithique tardif à l'Altaï. En Otte, M. (dir) : Préhistoire d'Anatolie : Génése de deux mondes, ERAUL, $85: 815-843$.

EsPaRzA, X. (1993): Los complejos Preauriñacienses: El Castelperroniense y el Protoauriñaciense en el Pirineo occidental. En Cabrera Valdés, V. (ed.): El Origen de hombre moderno en el Suroeste de Europa. UNED: 209-218.

FreEMAN, L.G. (1971): Los niveles de ocupación musteriense. En González Echegaray, J. \& Freeman, L.G. (cord) Cueva Morin. Publicaciones del Patronato de las cuevas prehistóricas de la provincia de Santander: 27-134.

Freeman, L.G. (1973): El musteriense. En González Echegaray, J. \& Freeman, L.G. (coord.): Cueva Morin. Publicaciones del Patronato de las cuevas prehistóricas de la provincia de Santander: 15-140.

FORTEA, J. (1995): Abrigo de la Viña. Informe y primera valoración de las campañas 1991. 1994. Excavaciones Arqueológicas en Asturias, 1991-94: 19-32.

FORTEA, J. (1999): Abrigo de La Viña. Informe y primera valoración de las campañas de 1995 a 1998. Excavaciones Arqueológicas en Asturias, 1995-1998: 31-41.

GOUEDO, J-M. (1990): Les technologies lithiques du Châtelperronien de la couche $X$ de la Grotte du Renne d'Arcy-sur-Cure (Yonne). En Farizy, C. (ed.): Paléolithique moyen récent et Paléolithique supérieur ancien en Europe. Mémoires du Musée de Préhistoire d'lle de France, $3: 305-308$.

GonzÁlez Echegaray, J. (1969): El paso del Paleolítico Medio al Superior en la costa cantábrica. Anuario de Estudios Atlánticos, 15: 273-279.

González Echegaray, J. \& Freeman, L.G. (1971): Cueva Morin. Publicaciones del Patronato de las cuevas prehistóricas de la provincia de Santander, VI, pág. 452.

González Echegaray, J. \& Freeman, L.G. (1973) Gueva Morin. Publicaciones del Patronato de las cuevas prehistóricas de la provincia de Santander, X, pág. 304.

González Echegaray, J. \& Freeman, L.G. (1978): Vida y muerte en cueva Morin. Institución Cultural de Cantabria. pág. 357.

GuILBAUD, M. (1993): Débitage from the Upper Castelperronian Level at Saint-Césaire. En Lévêque, F.; Backer, A. M. \& Guilbaud, M. (eds.) : Context of a Late Neandertal. Implications of Multidisciplinary Research for the Transition to Upper Paleolithic Adaptations at Saint-Césaire, Charente-Maritime, France. Monographs in Worlo Archaeology, 16:39-58.

Inizan, M-L.; Reduron, M.; Roche, H. \& Tixier, J. (1995): Technologie de la pierre taillée. C.R.E.P. pág. 199.

KozLOWSKY, J. (2000): The problem of cultural continuity between the Middle and the Upper Paleolithic in Central and Eastern Europe. En Bar-Yosef, O. \& Pilbeam, D. (eds.): The Geography of Neanderthal and Moderns Humans in Europe and the Greater Mediterranean: 77-105.

KOZLOWSKY, J. (2001): Origin and evolution of blade technologies in the Middie and Early Upper Palaeolithic. Mediterranean Archaeology and Archaeometry, 1 (1): 8-18.

KHun, S. L. (1995): Mousterian lithic technology, Princeton University Press, pág. 209 pags.

KHUN, S. L. (1996): Middle Palaeolithic responses to raw material quality: two Italian cases. Quaternaria Nova, VI: 261-275.

KHUN, S. L. \& BIETTI, A. (2000): The Late Middle and Early Upper Paleolithic in Italy. En BarYosef, O. \& Pilbeam, D. (eds.): The Geography of Neanderthal and Moderns Humans in Europe and the Greater Mediterranean: 49-76.

LAVILLE, H. \& HoYOS, M. (1994): Algunas precisiones sobre la estratigrafía y sedimentología de cueva Morin (Santander). En Bernaldo de Quirós, F. (ed): El cuadro geocronológico del Paleolítico Superior inicial. Monografías del Museo y Centro de Investigación de Altamira, 13: $200-209$. 
Lerol-Gourhan, Arl. (1971): Análișis polínico de cueva Morin. En González Echegaray, J. \& Freeman, L.G.: Cueva Morin. Publicaciones del Patronato de las cuevas prehistóricas de la provincia de Santander, VI: 357-365.

LocHT, J-L. (1990): Étude technologique et typologique du site paléolithique moyen du Rissori à Masnuy-St-Jean (Hainaut). Mémoires de Préhistoire Liégoise, 12 : 73 pág. y LXI láminas.

Maíllo FeRnÁndez, J.M. (e.p.): La production lamellaire de L'Aurignacien de la Grotte Morin (Cantabrie, Espagne). En Le-Brun, F. (ed) : Productions lamellaires attribuées à L'Aurignacien : Chaînes opératoires et perspectives techno-culturelles.

MARKS, A. \& VOLKMAN, W. (1983): Changing core reduction strategies: a technological shift from the Middle to the Upper Paleolithic in the Sourthern Levant. En Trinkaus, E. (ed.): The Mousterian Legacy: Human Biocultural Change in the Upper Pleistocene, B.A.R. International series, 164: 13-33.

Meignen, L. (1994): Paléolithique Moyen au Proche-Orient. Le phénomène laminaire. En Revillon, S. \& Tuffreau, A. (eds.): Les industries laminaires au Paléolithique Moyen. Dossier de Documentation Archeologique, $18: 125-159$.

OTTE, M. (1994) : Rocourt (Liège, Belgique): industrie laminaire ancienne. En Revillon, S. \& Tuffreau, A.: Les industries laminaires au Paléolithique Moyen. Dossier de Documentation Archeologique, $18: 180-186$.

OtTE, M.; Bö̈dA, E. \& Haesaerts, P. (1990): Rocourt: industrie laminaire archaïque. Helinium, $X X \mid X / 1: 3-13$

Otte, M. \& Derevianko, A. (2000) : Transformations techniques au Paléolithique de l'Altaï. En Otte, M. : Approches du comportement au Moustérien. BAA International Series: 833: 95 105.

Otte, M. ; Derevianko, A.; Taimagambeton, Z. \& Pétrine, V. (2000) : Paléolithique au Kazakhstan. En Otte, M. : Approches du comportement au Moustérien. BAR International Series: $833 ; 106-114$.

PElEgRIN, J. (1990): Observations technologiques sur quelques séries du Châtelperronien et du MTA B du sud-ouest de la France. En Farizy, C. (ed.): Paléolithique moyen récent et Paléolithique supérieur ancien en Europe. Mémoires du Musée de Préhistoire d’lle de France, $3: 195-201$

PELEGRIN, J. (1995): Technologie Lithique : Le Châtelperronien de Roc-de-Combe (Lot) et de La Côte (Dordogne). Cahiers du Quaternaire, 20, pág. 297.

Pelegrin, J. (2000) : Les technniques de débitage laminaire au Tardiglaciaire : critères de diagiose et quelques réflexions. En Valentin, B. \& Christensen, M. (eds) : L'Europe centrale et septentrionale au Tardiglaciaire. Actes de la Table-Ronde Nemours 1997, Memoires du Musée du lle de France, N. $^{\circ} 7: 73-86$.

RévILLION, S. (1994) : Les industries laminaires du Paléolithique moyen en Europe septentrionale. Publications du CERP, pág. 187.

RÉVILLION, S. \& TUFFreAU, A. (1994a) : Les industries laminaires au Paléolithique Moyen. Dossier de Documentation Archeologique, 18, pág. 193

ReVILLION, S. \& Tuffreau, A. (1994b) : Introduction. En Revillon, S. \& Tuffreau, A.: Les industries laminaires au Paléolithique Moyen. Dossier de Documentation Archeologique, 18 : 11-17.

RÉVILLION, S. \& TUfFREAU, A. (1994c) : Valeur et signification du débitage laminaire du gisement paléolithique moyen de Seclin (Nord). En Revillon, S. \& Tuffreau, A.: Les industries laminaires au Paléolithique Moyen. Dossier de Documentation Archeologique, 18: 19- 43.

RÉVILLION, S. \& CLIQUET, D. (1994) : Technologie du débitage laminaire du gisement paléolithique moyen de Saint-Germain-des-Vaux/Port Racine (secteur I) dans le contexte des industries du Paléolithique moyen du Massif Armoricain. En Revillon, S. \& Tuffreau, A.: Les industries laminaires au Paléolithique Moyen. Dossier de Documentation Archeologique, 18 : 45-62.

SARABIA, P. (1999): Aprovechamiento y utilización de materias primas líticas en los tecnocomplejos del Paleolítico en Cantabria. Tesis doctoral. Univ. de Cantabria, pág. 842.

SCHÄFER, J. \& RANOV, V.A. (1998): Middle Palaeolithic blade industries and the Upper Palaeolithic of Cantral Asia. En Otte, M. (dir) : Préhistoire d'Anatolie : Génése de deux mondes, ERAUL, $85: 785-814$.

SitliVy, V.; SobczYK, K.; Morawsky, W.; Zieba, A. \& EscutenalRe, C. (1999) : Piekary lia Palaeolithic industries: Preliminary results of a new multidisciplinary investigations. Préhistoire Europenne, 15: 45-64. 
Sitlivy, V.; SobczYk, K.; Kalicki, T.; Escutenaire, C.; Zieba, A. \& Kaczor, K. (1999): The New Palaeolithic Site of Ksiecia Jozefa (Cracow, Poland) with Blade and Flake Reduction. Préhistoire Europenne, 15: 87-111.

ŠKRDLA, P. (1996): The Bohunician reduction strategy. En Bietti, A. \& Grimaldi, S (eds.): Reduction processes for the European Mousterian, Quaternaria Nova, VI: 93-107.

SLIMAK, L. (1999): Mise en évidence d'une composante laminaire et lamellaire dans un complexe moustérien du Sud de la France. Paléo, $11: 89-109$.

TIXIER, J. (1984) : Lames. Préhistoire de la pierre taillée 2. Économie du débitage laminaire: 1319.

Vega del Sella, Conde de LA (1921): El Paleolítico de Cueva Morin (Santander) y Notas para la climatología Cuaternaria. Comisión de Investigaciones Paleontológicas y Prehistóricas, Memoria 29, pág. 168. 